O CONTEÚDO DO PRINCÍPIO NEMO TENETUR SE DETEGERE NA CORTE INTERAMERICANA DE DIREITOS HUMANOS E NO TRIBUNAL EUROPEU DE DIREITOS HUMANOS

\author{
Dissertação de Mestrado \\ Orientador: Professor Titular Dr. Antonio Magalhães Gomes Filho
}

UNIVERSIDADE DE SÃO PAULO

FACULDADE DE DIREITO

São Paulo - SP 


\section{ANDERSON RODRIGO SILVANO}

O CONTEÚDO DO PRINCÍPIO NEMO TENETUR SE DETEGERE NA CORTE INTERAMERICANA DE DIREITOS HUMANOS E NO TRIBUNAL EUROPEU DE DIREITOS HUMANOS

Dissertação apresentada à Banca Examinadora do Programa de Pós-Graduação em Direito, da Faculdade de Direito da Universidade de São Paulo, como exigência parcial para obtenção do título de Mestre em Direito, na área de concentração Direito Processual, sob a orientação do Professor Titular Dr. Antonio Magalhães Gomes Filho.

UNIVERSIDADE DE SÃO PAULO

FACULDADE DE DIREITO

São Paulo - SP 
Catalogação da Publicação

Serviço de Biblioteca e Documentação

Faculdade de Direito da Universidade de São Paulo

Silvano, Anderson Rodrigo

o conteúdo do princípio nemo tenetur se detegere na Corte Interamericana de Direitos Humanos e no Tribunal Europeu de Direitos Humanos / Anderson Rodrigo Silvano; orientador Prof. Dr. Antonio Magalhães Gomes Filho -- São Paulo, 2017.

$214 \mathrm{f}$.

Dissertação (Mestrado - Programa de Pós-Graduação em Direito Processual) - Faculdade de Direito, Universidade de São Paulo, 2017.

1. Direito de não produzir prova contra si mesmo. 2. Nemo tenetur se detegere (Processo Penal). 3. Prova contra si mesmo - autoincriminação . 4. Corte Interamericana de Direitos Humanos. 5. Tribunal Europeu de Direitos Humanos. I. Gomes Filho, Prof. Dr. Antonio Magalhães, orient. II. Título. 
Dedico este trabalho a minha mãe Helena e ao meu pai Antonio, seres iluminados que, com muito amor e cuidado, me ensinaram a sempre buscar ser melhor. A sua existência é o que traz felicidade em minha vida. 


\section{AGRADECIMENTOS}

Agradecer é reconhecer que nenhum homem é capaz de realizar qualquer obra sozinho. É a capacidade de reconhecer um gesto de bondade, uma atitude de carinho, uma ajuda, um elogio, uma assistência, um presente, uma gentileza... tenho muitos a quem agradecer!

Acima de tudo, a Deus, a quem diuturnamente recorro, rogando sua proteção e guia nos meus passos e pensamentos pelos caminhos da vida.

Ao meu orientador, Professor Antonio Magalhães Gomes Filho, pessoa por quem guardo o mais profundo respeito e admiração, por ter me dado a oportunidade de frequentar o curso de Pós-Graduação na Faculdade de Direito da Universidade de São Paulo, por confiar no projeto de dissertação apresentado e pelo seu valor humano, sempre afável, gentil, respeitoso e disponível aos seus alunos.

Aos meus irmãos Regiane e Ederson, pelo apoio e incentivo constantes e determinantes para a conclusão deste estudo.

A todos meus professores que se dedicaram profundamente ao trabalho de participarem comigo em minha construção como sujeito; professores que estiveram comigo na pré-escola, no fundamental, no ensino médio, na graduação e na pós-graduação, em cursos como música, informática, idiomas e que de inúmeras outras formas que me ajudaram/ajudam com que eu me expresse. De alguma forma, levo comigo com um enorme carinho e respeito.

A base desta dissertação se firmou no meu caminho da pós-graduação, por isso agradeço imensamente a todos os debates proporcionados/mediados principalmente pelos meus grandes Mestres da Faculdade de Direito da Universidade de São Paulo, professores Antonio Magalhães Gomes Filho, Gustavo Henrique Righi Ivahy Badaró, Marta Cristina Cury Saad Gimenes, Maria Thereza Rocha de Assis Moura, Antonio Scarance Fernandes, Maurício Zanoide de Moraes, José Raul Gavião de Almeida, Marcos Alexandre Coelho Zilli, Alexandre de Moraes e Maria Sylvia Zanella Di Pietro. 
A todos os colegas de turmas que passaram por mim, mas, especialmente, Francisco de Assis Garcia, Renan Barboza de Faria e Taimi Haensel, amigos de todas as horas, pela leitura atenta e crítica que possibilitou o aprimoramento do texto.

Aos meus queridos amigos Valdemar Rubens Marin, Sara Corrêa Fattori, Samira Mohammad Mughrabi, Carlos Eduardo Marques Gomes Junior, Fábio Carlos Ultramari e Gustavo Luigi Aguiar pelo apoio, carinho e inestimável ajuda com opiniões, correções e sugestões - todas acolhidas -, que contribuíram decisivamente para a versão final do presente trabalho. Sem suas respectivas ajudas, cada qual a sua maneira, os dias destinados à concretização deste trabalho seriam ainda mais longos.

Aos funcionários e bibliotecários da Velha e Sempre Nova Academia do Largo de São Francisco. Dentre os funcionários, um agradecimento especial deve ser feito ao meu precioso amigo Eduardo Maciel, por ter sempre uma palavra de apoio e conforto.

A biblioteca da Corte Americana de Direitos Humanos, pelo imprescindível material de pesquisa, rapidamente selecionado e fornecido.

Aos meus pais, irmãos e demais amigos, por todo amor e carinho com que me cercaram todos esses anos e por me ensinarem tudo sobre força de vontade, perseverança e fé.

O maior agradecimento, no entanto, só poderia ser para minha mãe, sem dúvida a mulher mais forte, incrível, batalhadora, inteligente, amorosa (com animais e plantas, inclusive), parceira e generosa que existe. Sua gigantesca e luta contra o câncer me ensinou que não existe dificuldade que não possa ser superada. Muito obrigado, meu anjo.

Ao caos que nos move! 
"Quando uma criatura humana desperta para um grande sonho e sobre ele lança toda a força de sua alma, todo o universo conspira a seu favor."

\section{Johann Wolfgang von Goethe}

“Aprender é a única coisa que a mente nunca se cansa, nunca tem medo e nunca se arrepende." 


\section{RESUMO}

SILVANO, A. R. O conteúdo do princípio nemo tenetur se detegere na Corte Interamericana de Direitos Humanos e no Tribunal Europeu de Direitos Humanos.

2017. 213 f. Tese (Mestrado). Faculdade de Direito, Universidade de São Paulo, São Paulo, 2017.

Nos últimos anos, o interesse em questões envolvendo direitos humanos tem crescido enormemente. Instituições encarregadas da aplicação dos direitos humanos estabelecidos em tratados internacionais gastam grande parte do seu tempo lidando com supostas violações que ocorrem durante o processo penal. No futuro essas questões se tornarão ainda mais importantes, devido ao resultado da crescente internacionalização da administração da justiça. No presente trabalho, a jurisprudência acerca do princípio nemo tenetur se detegere, na Corte Interamericana de Direitos Humanos e na Corte Europeia de Direitos Humanos, dois órgãos internacionais mais importantes e influentes que lidam com essas questões, é apresentada e analisada criticamente. O princípio que assegura ao acusado o direito de não se autoincriminar é certamente uma das mais complexas garantias existentes no corpo dos direitos fundamentais aplicados no contexto do processo penal. Enquanto o problema central é claro, muitas questões específicas são contestadas e não há acordo sobre a estrutura da garantia. A jurisprudência crescente de ambas as Cortes detalha o significado e alcance de muitos dos direitos humanos garantidos - o privilégio contra a autoincriminação, inclusive -, e deveres estaduais correlatos. De igual importância, as decisões e opiniões enunciam regras de prova e dos demais direitos processuais aplicáveis aos casos conhecidos e julgados pelas Cortes. Comparar as decisões e as opiniões de ambos os Órgãos é, portanto, particularmente útil para avaliar o aperfeiçoamento e as limitações do sistema. O processo de comparação demonstrou que, sem embargo da existência de muitas semelhanças, as decisões de ambas as Cortes apresentam significativas diferenças. A final, a atual proteção conferida pela Corte Americana é a que melhor ampara o direito de defesa do acusado e contribui para a efetivação do justo processo.

Palavras-chave: Nemo tenetur se detegere. Privilégio contra a autoincriminação. Direito de não produzir prova contra si mesmo. Direito ao silêncio. Direito a não autoincriminação. 


\begin{abstract}
SILVANO, A. R. The content of nemo tenetur se detegere principle in Inter-American Court of Human Rights and in European Court of Human Rights. 2017. 213 f. Thesis (Master). Faculty of Law, University of São Paulo, São Paulo, 2017.

Interest in human rights has grown enormously over the past years. Institutions charged with the implementation of human rights, as set out in international treaties, spend a great deal of their time dealing with alleged violations that take place during criminal proceedings. In the future such issues will become even more important as a result of the increasing internationalization of the administration of justice. In this work, the case-law about nemo tenetur se detegere principle in Interamerican Court of Human Rights and in European Court of Human Rights, two of the most important and influential international bodies dealing with such issues, is presented and critically examined. The privilege against self-incrimination is certainly one of the most complex guarantees in the entire body of fundamental rights applicable in the context of criminal proceedings. While the basic problem is clear, many specific issues are contested and there is no agreement on the structure of the guarantee. The growing jurisprudence of both Courts details the meaning and scope of many of the guaranteed human rights - including the privilege against selfincrimination -, and correlative state duties. Of equal importance, the Court's decisions and opinions enunciate evidentiary and procedural rules applicable to those appearing before the Courts. Compare the decisions and opinions of the Courts are thus particularly useful in assessing the accomplishments and limitations of the system. The comparison process has shown that, notwithstanding the existence of many similarities, the decisions of both Courts have significant differences. At final, the current protection afforded by the American Court is the one that best sustains the accused defense and contributes to the realization of a fair trial.
\end{abstract}

Key-words: Nemo tenetur se detegere. Privilege against self-incrimination. Right not to produce evidence against himself. Right to silence. Right not to self-incrimination. 


\section{SUMÁRIO}

INTRODUÇÃO 14

\section{CAPÍTULO I - PERSPECTIVA HISTÓRICA DO PRINCÍPIO NEMO TENETUR}

SE DETEGERE 16

1. ORIGENS E DESENVOLVIMENTO 16

1.1. Primeira etapa: nemo tenetur seipsum accusare; nemo tenetur prodere seipsum 19

1.2. Segunda etapa: no person shall be compelled in any criminal case to be a witness against himself. 23

1.3. Terceira etapa: o "you have a right to remain silent" 27

1.3.1. Segue: o "you have a right to remain silent", nos dias atuais 32

2. PARA ONDE IREMOS A PARTIR DAQUI? 35

\section{CAPÍTULO II - O SISTEMA INTERAMERICANO DE PROTEÇÃO AOS

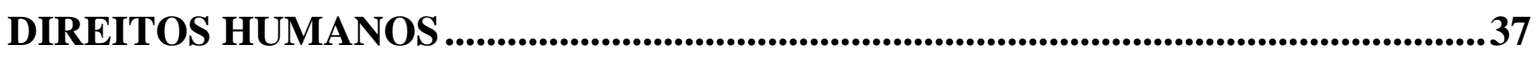

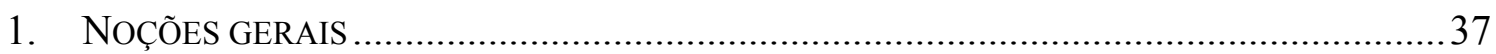

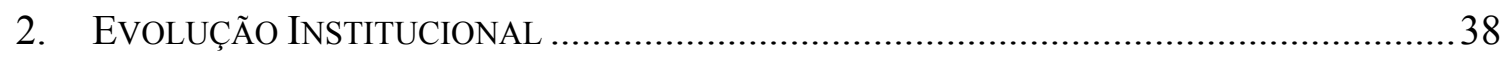

2.1. A Nona Conferência Internacional Americana: a Declaração de Direitos e Deveres do Homem e a criação da Comissão Interamericana de Direitos Humanos. 38

2.2. A Convenção Americana sobre Direitos Humanos............................................ 41

2.3. Outros instrumentos destinados à proteção dos direitos humanos.....................43

3. A CORTE INTERAMERICANA DE DiREITOS HuMANOS: SUA COMPOSIÇÃO E JURISDIÇÃO 44

3.1. Competência Consultiva.................................................................................. 45

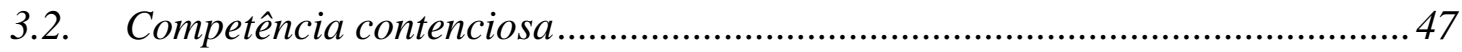

3.2.1. Procedimento utilizado na competência contenciosa .................................... 48

4. DESAFIOS DO SISTEMA INTERAMERICANO DE PROTEÇÃO DOS DIREITOS HUMANOS ....51

5. A ANÁLISE DA JURISPRUDÊNCIA DA CORTE INTERAMERICANA: ESCLARECIMENTOS.. 56 


\section{CAPÍTULO III - O DEVIDO PROCESSO LEGAL E A CORTE INTERAMERICANA DE DIREITOS HUMANOS ....................................................662}

1. POSTULAdOS FUNDAMENTAIS DO DIREITO PROCESSUAL: BREVES NOÇÕES ................62

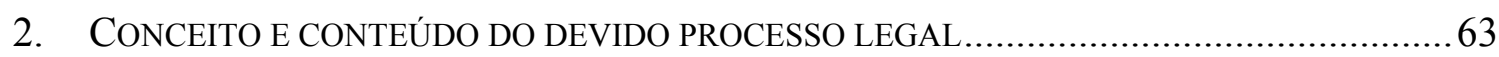

3. O DEVIdo PRocesso legal na CONVEnÇÃo AmERICANA DE Direitos Humanos .65

4. A CONCEPÇÃO DA CORTE INTERAMERICANA SOBRE O DEVIDO PROCESSO LEGAL: ESPECIFICIDADES

\section{CAPÍTULO IV - A INTERPRETAÇÃO DA CORTE INTERAMERICANA DE DIREITOS HUMANOS ACERCA DO PRINCÍPIO NEMO TENETUR SE

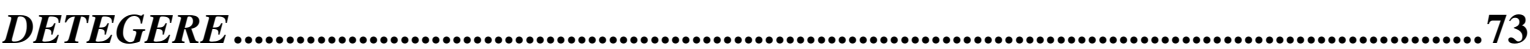

1. O DIREITO DE NÃO PRODUZIR PROVA CONTRA SI MESMO E SEUS EFEITOS...................73

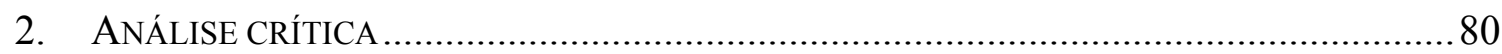

\section{CAPÍTULO V - A PROTEÇÃO DOS DIREITOS HUMANOS NA EUROPA...........84}

1. História da Corte Europeia de Direitos Humanos E SUA EVOluÇão.................84

2. Estrutura atual da Corte Europeia de Direitos Humanos ...........................87

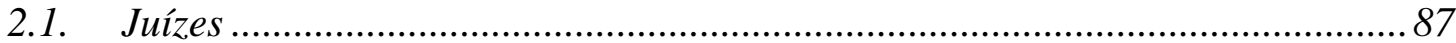

2.2. Organização da Corte Europeia de Direitos Humanos .....................................88

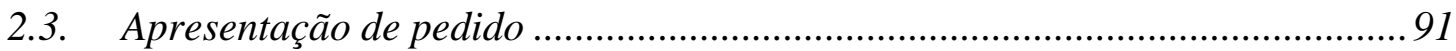

2.4. Especificidades da fase de instrução/audiência ............................................... 92

3. COMPETÊnCIA dA Corte Europeia de Direitos Humanos .................................... 94

3.1. Competência consultiva - elementos ................................................................ 95

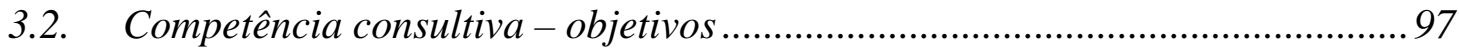

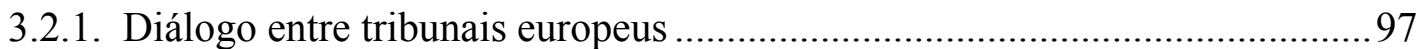

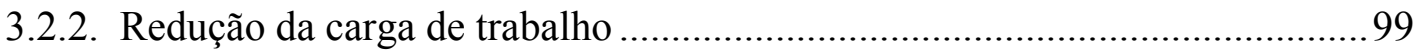

4. Característica das Decisões da Corte Europeia de Direitos Humanos

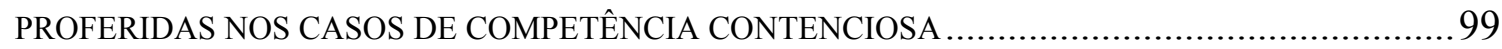

4.1. Manutenção do status quo enquanto pendente o julgamento .........................101

4.2. Reparação pecuniária razoável (Just satisfaction)..........................................102 


\section{CAPÍTULO VI - O PRINCÍPIO NEMO TENETUR SE DETEGERE NA CORTE EUROPEIA DE DIREITOS HUMANOS

1. A CONVENÇÃO EUROPEIA E O PRIVILÉGIO CONTRA A AUTOINCRIMINAÇÃO..... 104

2. O RECONHECIMENTO DO PRINCÍPIO NEMO TENETUR SE DETEGERE NA JURISPRUDÊNCIA

DA CORTE Europeia de Direitos Humanos 106

3. DEFININDO O PRINCÍPIO NEMO TENETUR SE DETEGERE 108

3.1. Em quais tipos de jurisdição o princípio contra a autoincriminação se aplica? 111

3.2. Quais provas estariam no âmbito de proteção do princípio nemo tenetur se detegere? 115

3.3. Seria o princípio nemo tenetur se detegere um direito absoluto? 116

3.4. Existe um "direito a ser advertido"? 119

4. REFINAMENTO, CONTENÇÃO OU RECUO? ANÁLISE DA JURISPRUDÊNCIA DA CORTE EUROPEIA DE DiREITOS HUMANOS APÓS O CASO SAUNDERS 120

4.1. Obrigação de depor imposta pela lei, sob ameaça de sanção 123

4.2. Emprego de coerção física e/ou psíquica: os métodos intrusivos de investigação. 128

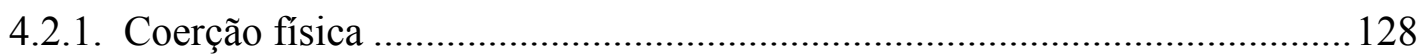

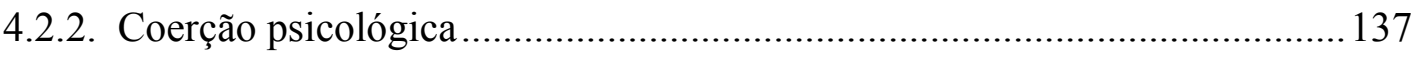

4.2.3. Coerção psicológica empregada em testemunhas. Proteção do princípio nemo tenetur se detegere?

4.3. Coerção exercida através do uso de técnicas de investigações secretas 149

5. SERIA POSSÍvel SISTEMATIZAR O POSICIONAMENTO DA CORTE EUROPEIA DE Direitos Humanos?

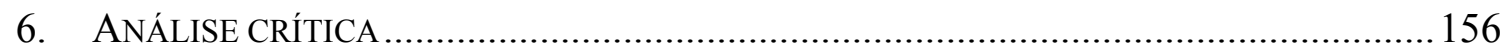

7. Súmulas dos Julgados ReAlizados Pela Corte Europeia DE DiReitos HUMANOS

7.1. Casos em que houve o reconhecimento da violação ao princípio nemo tenetur se detegere

7.2. Casos em que não houve o reconhecimento da violação ao princípio nemo tenetur se detegere 
CAPÍtULO VII - O PRINCÍPIO NEMO TENETUR SE DETEGERE NA JURISPRUDÊNCIA DA CORTE EUROPEIA DE DIREITOS HUMANOS E NA CORTE INTERAMERICANA DE DIREITOS HUMANOS: UMA ANÁLISE

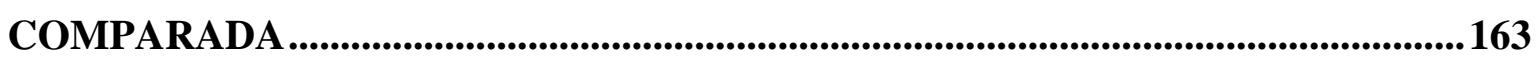

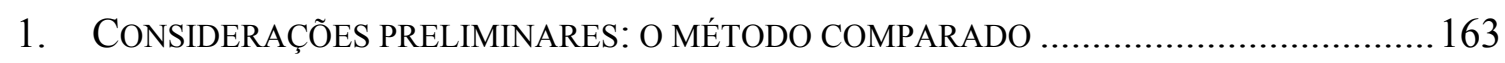

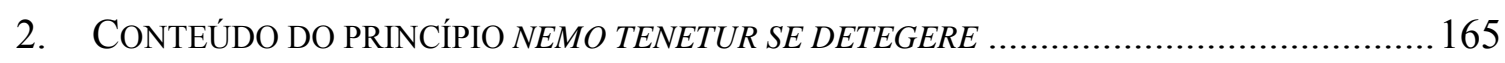

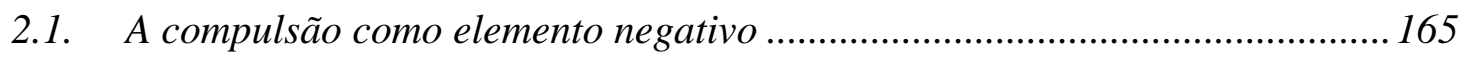

2.2. A presunção de inocência como elemento positivo ...........................................169

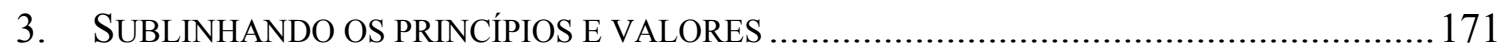

3.1. Garantir o julgamento justo: proibição da tortura .........................................172

3.2. Respeito à dignidade da pessoa humana.......................................................... 175

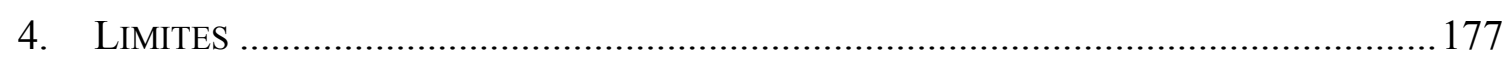

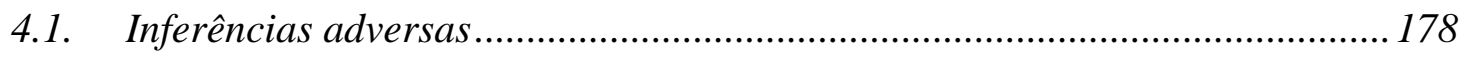

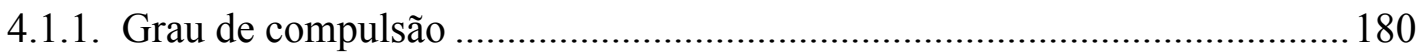

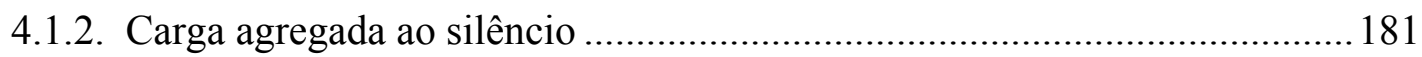

4.1.2.1. Situações que demandam uma explicação ................................... 181

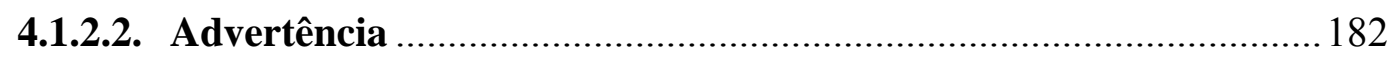

4.1.2.3. Respeito à presunção de inocência ................................................. 182

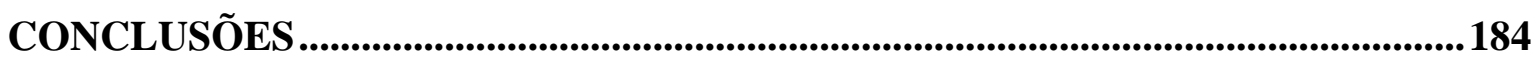

REFERÊNCIAS BIBLIOGRÁFICAS....................................................................187

CASOS UTILIZADOS - CORTE INTERAMERICANA DE DIREITOS HUMANOS

OPINIÕES CONSULTIVAS - CORTE INTERAMERICANA DE DIREITOS

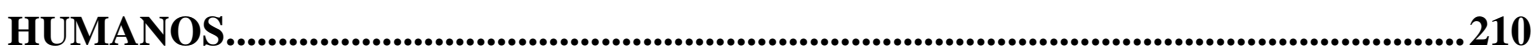




\section{INTRODUÇÃO}

Nemo tenetur se detegere. Ninguém é obrigado a se descobrir.

O princípio que assegura ao acusado o direito a não se autoincriminar possui raízes profundas na história do processo penal, sendo, hoje, largamente reconhecido como um inalienável e abrangente direito fundamental que assegura ao acusado a impossibilidade de sofrer qualquer sanção pelo seu exercício ${ }^{1}$.

Além do seu reconhecimento no processo penal moderno de diversos países, o princípio é também reconhecido em diversas Cortes Internacionais.

Nesse sentido, tanto a Corte Europeia de Direitos Humanos, como a Corte Interamericana de Direitos Humanos, tribunais internacionais cuja jurisdição é reconhecida por Estados soberanos, oferecem ampla proteção ao direito de o indivíduo permanecer em silêncio.

Como ambas as Cortes possuem a função precípua de julgar casos envolvendo violações de direitos humanos, o processo de comparação de suas respectivas jurisprudências torna-se proveitoso e útil.

Embora existam diversas peculiaridades regionais, o que certamente afeta o desenvolvimento jurisprudencial dos dois sistemas acima citados, os princípios e valores invocados no reconhecimento do direito a não autoincriminação são semelhantes, podendo ser mencionadas, a título de exemplo, a dignidade da pessoa humana, a presunção de inocência e o direito ao julgamento justo.

\footnotetext{
1 De opinião diversa, Eugênio Pacelli de Oliveira, sustenta que "reina entre nós a mais completa incompreensão acerca do alcance e da respectiva fundamentação do nemo tenetur se detegere". Mencionado autor defende que "O que deve ser protegido, em qualquer situação, é a integridade, física e mental, do acusado, bem como a sua capacidade de autodeterminação, daí por que são inadmissíveis exames como o do soro da verdade ou de ingestão de qualquer substância química para tal finalidade. E mais: deve ser também protegida a dignidade da pessoa humana, a vedar qualquer tratamento vexaminoso ou ofensivo à honra do acusado, e o reconhecimento do princípio da inocência. Reputamos, por isso, absolutamente inaceitável a diligência policial conhecida como reprodução simulada ou reconstituição dos fatos (art. $7^{\circ}, \mathrm{CPP}$ ). (...) Não enxergamos como a coleta de manuscrito de alguém pode afetar quaisquer dos valores protegidos pelo princípio da não autoincriminação ou do direito ao silêncio, parecendo-nos exorbitante do âmbito de proteção da norma constitucional a referida decisão. Mantendo-se semelhante ponto de vista, em breve também não se aceitará mais a diligência probatória intitulada reconhecimento de pessoas, conforme previsão do art. $226 \mathrm{e}$ seguintes do CPP, tendo em vista que ali também se exige um comportamento ativo do acusado. Por que razão quem pode se recusar a fornecer padrões gráficos estaria obrigado a se posicionar, de frente, de perfil, de costas, contra a sua vontade e contra os seus interesses?". Sobre o assunto, cf. E. P. OLIVEIRA. Curso de processo penal, p. 390-391.
} 
Não obstante, no que toca à proteção, a jurisprudência da Corte Interamericana de Direitos Humanos difere significativamente da jurisprudência da Corte Europeia de Direitos Humanos, tanto no escopo como nos limites.

O objetivo central da pesquisa é, portanto, oferecer um estudo comparado sobre o tratamento conferido pelas Cortes Regionais de Direitos Humanos ao princípio nemo tenetur se detegere.

Começaremos expondo as origens e a evolução do princípio nemo tenetur. $\mathrm{O}$ estudo da evolução do direito a não autoincriminação apresenta-se de grande valia para a compreensão do princípio nos diversos ordenamentos.

O mais importante aspecto do estudo histórico consiste justamente em conhecer o assentamento das premissas sobre os quais o princípio se desenvolveu ao longo da história.

Num segundo passo, serão objeto de exame as Cortes Regionais de direitos humanos escolhidas para o presente estudo. Serão analisados os eventos históricos e sociais que motivaram a criação de tais órgãos, bem como sua estrutura e funcionamento. Tais elementos fornecem subsídios para a compreensão da forma que o princípio é reconhecido nas respectivas jurisdições.

Após, o princípio em questão será estudado sob o enfoque jurisprudencial de cada Corte, com destaque nas decisões mais icônicas. Na Corte Europeia de Direitos Humanos, o realce será dado a partir da decisão que reconheceu o princípio como parte integrante do direito ao julgamento justo (fair trial), já que a Convenção Europeia de Direitos Humanos não prevê o direito ao silêncio, manifestação mais tradicional do princípio nemo tenetur se detegere.

A situação é, por sua vez, diferente na Corte Interamericana de Direitos Humanos. Como a Convenção Americana sobre Direitos Humanos contempla o princípio nas disposições do artigo 8 , o estudo se concentrará nas repercussões do princípio e nas provas que dependam da colaboração do acusado.

Serão analisadas, dentro do estudo comparado, diversos valores reconhecidos como fundamentais pelas Cortes, como o devido processo, a ampla defesa, dignidade da pessoa humana e a presunção de inocência.

Enfim, a proposta do presente trabalho é tentar elucidar os rumos que, na atualidade, têm adotado as Cortes acima mencionadas sobre o princípio nemo tenetur se detegere, com o intuito de fornecer subsídios para a preservação do processo penal, sem tornar inviável a persecução penal. 


\section{CONCLUSÕES}

Após analisar e comparar a jurisprudência da Corte Interamericana de Direitos Humanos e da Corte Europeia de Direitos Humanos acerca do privilégio contra a autoincriminação, consubstanciado na máxima nemo tenetur se detegere, podemos concluir que, para ambas as Cortes, mencionado direito é compreendido como uma especial salvaguarda, notadamente no âmbito da justiça criminal, que goza de especial proteção.

Entretanto, embora o cotejo das decisões das duas Cortes Regionais demonstre a existência de muitas semelhanças, significativas diferenças também existem.

Como inexiste previsão do princípio nemo tenetur se detegere na Convenção Europeia, o Tribunal de Estrasburgo, no julgamento do caso Funke, o deduziu a partir da interpretação do direito ao julgamento justo, assegurado no artigo 6. A partir de então, a proibição de se exigir a autoincriminação passou a fazer parte de sua substancial jurisprudência.

O ponto central de tal proibição, segundo a jurisprudência da Corte Europeia, seria assegurar o direito ao silêncio do acusado, garantindo-lhe a livre escolha para responder a quaisquer questões formuladas na instância penal. Conforme a decisão proferida no caso Saunders, este objetivo se afinaria perfeitamente com os valores básicos que o princípio visa proteger: garantir o julgamento justo e a dignidade da pessoa humana.

A interpretação da Corte Europeia se firmou no sentido de que o princípio nemo tenetur se detegere, além de abrigar o silêncio do acusado, assegura a proibição de compelir o indivíduo a fornecer documentos autoincriminatórios.

Contudo, está longe de ser um princípio absoluto.

Foi no caso John Murray que a Corte Europeia acatou a ideia de que, em determinadas circunstancias, poderia a lei permitir a apreensão de inferências negativas extraídas a partir do silêncio do acusado, sem que isso violasse a Convenção Europeia.

Para tanto, basta que o acusado tenha sido devidamente informado acerca de seu direito de permanecer em silêncio e compreendido a possibilidade de inferências negativas, caso opte em permanecer calado; que o grau de compulsão, caso empregado, seja justificado e não configure tortura, situação essa aferida a partir do caso concreto e incida sobre provas que tenham existência independente; que a situação exija uma 
explicação; e que o princípio da presunção de inocência seja respeitado, também no sentido de não permitir a inversão do ônus da prova em prejuízo do acusado, o que será aferido no caso concreto.

Nada obstante, merece registro o fato de que a jurisprudência mais recente da Corte Europeia tem, gradualmente, apresentado os mais diversos argumentos exceptivos, que, a final, minam a proteção outrora garantida pelo direito a não autoincriminação.

Por conta de sua inconstância, a futura aplicação do princípio nemo tenetur se detegere, na Corte Europeia de Direitos Humanos, constitui um leque de incertas possibilidades.

No âmbito interamericano, o princípio nemo tenetur se detegere vem expresso no texto da Convenção.

A jurisprudência da Corte Interamericana ressalta os princípios da dignidade da pessoa humana e da presunção de inocência e enfatiza que a proteção abrange outros múltiplos valores, cabendo ao Estado comprovar a veracidade da acusação, sem esperar que o indivíduo coopere sob pena de padecer qualquer sofrimento ou punição, seja física, seja psíquica. Nesse sentido, a Corte Interamericana se afasta de qualquer resquício dos métodos e princípios do processo inquisitório.

Como destacado no caso Baena Ricardo y otros, a especial proteção, na esfera interamericana, se estende a todos os processos que estejam sob supervisão estatal, independentemente de sua natureza penal ou não penal.

Ademais, a Corte Interamericana consagra que o princípio confere ampla proteção ao acusado, incidindo desde a etapa inicial da persecução penal (caso Maritza Urrutia).

É possível afirmar, baseando-se nos casos analisados, que, para a Corte Interamericana, o privilégio contra a autoincriminação possui duas facetas: a primeira, decorrente do texto da Convenção, assegura que os Estados signatários do tratado não empreguem qualquer tipo de compulsão objetivando obter provas incriminatórias; e a segunda, reflexo da anterior, que eventuais depoimentos autoincriminatórios obtidos sob coação sejam inadmissíveis como prova num julgamento criminal.

Não encontramos nos casos analisados no âmbito interamericano questões envolvendo compulsão para entrega de documentos potencialmente autoincriminatórios. Mas é possível supor, baseando-se na larga e especial proteção conferida pela Corte, que tal postura encontraria obstáculos no texto da Convenção. 
Em contraste com a jurisprudência da Corte Europeia, a Corte Interamericana estabeleceu a impossibilidade absoluta de se extrair inferências negativas a partir do silêncio do acusado (caso López Álvarez).

A abordagem da Corte Americana, assim, protege não somente aqueles beminformados de seus direitos, como, também, aqueles mais vulneráveis.

No contexto do quadro de violações enfrentados pela Corte Americana, que, como dito, envolvem casos de terrorismo, traição à pátria, tráfico de drogas, leis que limitam garantias processuais, dentre outras, ainda que inexista maior precisão doutrinária sobre o conteúdo dos direitos previstos no artigo 8 da Convenção, a interpretação desenvolvida pela Corte Americana é que melhor ampara o direito de defesa do acusado, pois, além de preservar, de forma absoluta, a dignidade da pessoa humana e a presunção de inocência, contribui para a efetivação do justo processo. 


\section{REFERÊNCIAS BIBLIOGRÁFICAS}

ACOSTA, Walter P. O processo penal. 13. ed. Rio de Janeiro: Editora do Autor, 1978.

ALAIMO, Giuseppe. Sulla omissione dell'avvertimento all'imputato circa la facoltà di non rispondere. Rivista Italiana di Diritto e Procedura Penale, Milano, p. 676-692, 1979.

ALCALÁ-ZAMORA Y CASTILLO, Niceto; LEVENE HIJO, Ricardo. Derecho procesal penal. Buenos Aires: Guillermo Kraft, 1945. t. 2 e 3.

ALLENA, Gianni. Riflessioni sul concetto di incostituzionalità della prova nel processo penale. Rivista Italiana di Diritto e Procedura Penale, Milano, p. 506-528, 1989.

ALSCHULER Albert. A peculiar privilege in historical perspective: the right to remain silent. 94 Michigan Law Review 2625, 1995.

ÁLVAREZ, Tomás Prieto. La dignidad de la persona - núcleo de la moralidad y el orden públicos, límite al ejercicio de liberdades públicas. Cizur Menor (Navarra): Civitas, 2005.

AMAR, A. R.; LERNER, R. L. Fifth amendment first principles: the self-incrimination clause (1995). Faculty Scholarship Series. Paper 993. Disponível em http://digitalcommons.law.yale.edu/fss_papers/993, acesso em 18 de fevereiro de 2015.

AMBOS, Kai. The right of non-self-incrimination of witnesses before the ICC, LJIL 2002, p. 155. Disponível em SSRN: http://ssrn.com/abstract=2036397, acesso em 27.01.2015.

; CHOUKR, Fauzi Hassan. A reforma do processo penal no Brasil e na América Latina. São Paulo: Método, 2001.

ANDRADE, Manuel da Costa. Sobre as proibições de prova em processo penal. Coimbra: Coimbra Ed., 1992.

AQUINO, José Carlos G. Xavier. A prova testemunhal no processo penal brasileiro, São Paulo: Saraiva, 1987.

ARANHA, Adalberto José Q. T. de Camargo. Da prova no processo penal. 5. ed. São Paulo: Saraiva, 1999.

ASHWORTH, Andrew. REDMAYNE, Mike. The criminal process. 4. ed. New York: Oxford University Press Inc., 2010. 
AVANZINI Alfredo. L'esame dibattimentale delle fonti di prova personali. In: La conoscenza del fatto nel processo penale. Milano: Giuffrè, 1992.

ÁVILA, Humberto Bergmann. A distinção entre princípios e regras e a redefinição do dever de proporcionalidade. Revista de Direito administrativo, Rio de Janeiro, v. 215, p. 151-179, jan./mar. 1999.

AZEVEDO, David Teixeira de. O interrogatório do réu e o direito ao silêncio. RT, São Paulo, v. 682, p. 285-298, ago. 1992.

BADARÓ, Gustavo Henrique Righi Ivahy. Processo penal. $3^{\mathrm{a}}$ ed. São Paulo: Revista dos Tribunais, 2015.

Ônus da prova no direito processual penal brasileiro. Tese (Doutorado). Faculdade de Direito de São Paulo, Universidade de São Paulo, São Paulo, 2002.

BAPTISTA, Francisco das Neves. O mito da verdade real na dogmática do processo penal. Rio de Janeiro: Renovar, 2001.

BARANDIER, Antonio Carlos. Confissão: supremo objetivo da investigação. Revista Brasileira de Ciências Criminais, São Paulo, v. 3, p. 79-82, jul./set. 1993.

BARANDIER, Márcio Gaspar. A prova ilícita no processo penal. Breves comentários. Revista Brasileira de Ciências Criminais, São Paulo, v. 2, p. 73-76, abr./jun. 1993.

BARGIS, Marta. In tema di interrogatório "libero" di un imputato di reati connessi. Rivista Italiana di Diritto e Procedura Penale, Milano, p. 850-885, 1979.

In tema di interrogatório del coimputato. Rivista Italiana di Diritto e Procedura Penale, Milano, p. 1589-1596, 1979.

. Le dichiarazioni di persone imputate in un procedimento connesso. Milano: Giuffrè, 1994.

BARROS, Antônio Milton de. A defesa do acusado e sua intervenção no interrogatório judicial. Revista Brasileira de Ciências Criminais, São Paulo, v. 14, p. 131-140, 1996.

BARROS, Marco Antonio de. A busca da verdade no processo penal. Tese (Doutorado). Faculdade de Direito de São Paulo, Universidade de São Paulo, São Paulo, 2001.

BARROSO, Luís Roberto. Interpretação e aplicação da Constituição. 3. ed. São Paulo: Saraiva, 1999.

. Temas de direito constitucional. 2. ed. Rio de Janeiro: Renovar, 2002. 
$\mathrm{BASCH}$, Fernando Felipe. The doctrine of the inter-american court of human rights regarding states' duty to punish human rights violations and its dangers. American University International Law Review 23, no.1 (2013): 195-229.

BASTOS, Celso Ribeiro; MARTINS, Ives Gandra. Comentários à Constituição do Brasil de 1988. São Paulo: Saraiva, 1989. v. 2.

BECCARIA, Cesare. Dei delitti e delle pene. Roma: Garzanti Libri, 2000.

BEDAQUE, José Roberto dos Santos. Poderes instrutórios do juiz. 2. ed. São Paulo: Revista dos Tribunais, 1994.

BELLAVISTA, Girolamo. Confessione. In: Enciclopedia del diritto. Varese: Giuffrè, 1972. v. 8.

. Difesa giudiziaria penale. In: Enciclopedia del diritto. Varese: Giuffrè, 1972. v.

12.

. Lezioni di diritto processuale penale. Milano: Giuffrè, 1956.

BENETI, Sidnei Agostinho. O processo na Suprema Corte dos Estados Unidos. In: $O$ Judiciário e a Constituição. Coord. TEIXEIRA, Sálvio de Figueiredo. São Paulo: Saraiva, 1996.

BENTZ, Andrew. The original public meaning of the fifth amendment and pre-miranda silence (March 13, 2012). Virginia Law Review, Vol. 98, 2012. Disponível em SSRN: http://ssrn.com/abstract=2021116, acesso em 27.01.2015.

BERALDO, Luís Fernando Silveira. Limites aos poderes instrutórios do juiz crimial, Tese (Mestrado). Faculdade de Direito de São Paulo, Universidade de São Paulo, São Paulo, 2006.

BETTIOL, Giuseppe. Istituzioni di diritto e procedura penale. Padova: CEDAM, 1966.

BOBBIO, Norberto. O positivismo jurídico. Trad. Márcio Pugliese. São Paulo: Ícone, 1995.

. Teoria do ordenamento jurídico. 10. ed. Trad. Maria Celeste Cordeiro Leite dos Santos. Brasília: Universidade de Brasília, 1997.

BONAVIDES, Paulo. Curso de direito constitucional. 10. ed. São Paulo: Malheiros, 2000.

BONETTI, Michele. Riservatezza, diritti dell'uomo e processo penale: aspetti problematici. L'Indice Penale, Padova, p. 581-642, 1995. 
BUTTARELLI, Giovanni. Le nuove modalità di accertamento del reato di guida in stato di ebbrezza tra prove legali e diritto di difesa. Cassazione Penale, p. 2231-2243, 1990.

BUZZELLI, Silvia. Il contributo dell'imputato alla ricostruzione del fatto. In: $L a$ conoscenza del fatto nel processo penale. Milano: Giuffrè, 1992.

CALAMANDREI, Iolanda. La collaborazione processuale di imputati e testimoni nei sistemi di “common law". Rivista italiana di Diritto e Procedura Penale, Milano, p. 240$261,1986$.

CAMAZANO, Joaquín Brage. Los límites a los derechos fundamentales. Madrid: Dykinson, 2004.

CAMPO, Orazio. Interrogatorio dell'imputato. In: Enciclopedia del diritto. Varese: Giuffrè, 1972. v. 22.

CANOTILHO, J. J. Gomes. Direito constitucional e teoria da Constituição. 3. ed. Coimbra: Almedina, 1999.

CANTONE, Raffaele. Il giusto processo. Napoli: Simone, 2001.

CAPPELLETTI, Mauro. La testemonianza della parte nel sistema dell'oralità. Milano: Giuffrè, 1974.

. The judicial process in comparative perspective. Oxford: Clarendon Press, s.d.

CARNELUTTI, Francesco. Diritto e processo. Napoli: Morano, 1958.

. Lezioni sul processo penale. Roma: Ateneo, 1946.

. Principi del processo penale. Napoli: Morano, 1961.

CARRARA, Francesco. Programma del corso di diritto criminale. 10. ed. Florença: Fratelli Cammelli, 1907. Parte Geral, v. 2.

CARRIO, Alejandro D. Garantías constitucionales em el proceso penal 3. ed. Buenos Aires: Hammurabi, 1997.

CARVALHO, Ricardo Cintra Torres de. A inadmissibilidade da prova ilícita no processo penal - um estudo comparativo das posições brasileira e norte-americana. Revista Brasileira de Ciências Criminais, São Paulo, v. 12, p. 162-170, out./dez. 1995. 
CASTANHEIRA, Beatriz Rizzo. Organizações criminosas no direito penal brasileiro: o estado de prevenção e o princípio da legalidade estrita. Revista Brasileira de Ciências Criminais, São Paulo, v. 24, p. 99-124, out./dez. 1998.

CASTRILlO, Eduardo de Urbano e MORATO, Miguel Angel Torres. La prueba ilícita penal. Estudio jurisprudencial. 2. ed. Navarra: Aranzadi, 2000.

CATALDO, Maria Elisabetta. Imputato e "testimone assistito" nel processo penale francese. In: Le nuove leggi penali. Milano: CEDAM, 1998.

CEIA, Eleonora Mesquita. A Jurisprudência da Corte Interamericana de Direitos Humanos e o Desenvolvimento da Proteção dos Direitos Humanos no Brasil. Revista da EMERJ, Rio de Janeiro, v. 16, n. 61, p. 113-152, jan./mar. 2013.

CHIAVARIO, Mario. Convenzione europea dei diritti dell'uomo e riforma del processo penale. Rivista Italiana di Diritto e Procedura Penale, Milano, p. 661-674, 1970.

. Garanzie individuali ed efficienza del processo. In: Il giusto processo. Milano: Giuffrè, 1998.

. Il problema dell'autodifesa nel processo penale. Bologna: Zanichelli, 1977.

. Inizio del procedimento penale e tutela costituzionale di diritto di difesa. Rivista Italiana di Diritto e Procedura Penale, Milano, p. 613-620, 1963.

La presunzione d'innocenza nella giurisprudenza della Corte Europea dei diritti dell'uomo. In: Studi in ricordo di Giandomenico Pisapia. Milano: Giuffrè, 2000. v. 2.

. Una sentenza chiarificatrice sulla garanzia dell'autodifesa nel procedimento per decreto penale. Rivista Italiana di Diritto e Procedura Penale, Milano, p. 304-308, 1968.

CHIESA, Luis E. Beyond torture: the nemo tenetur principle in borderline cases (May 2009). Boston College Third World Journal, Forthcoming. Disponível em SSRN: http://ssrn.com/abstract=1401401, acesso em 27.01.2015.

CHIMENTI, Francesco. O processo penal e a verdade material (teoria da prova). Rio de Janeiro: Forense, 1995.

CICAGNA Jr., Dilermando. Investigação de paternidade - Provas - DNA - Recusa ao exame. Revista do Advogado, São Paulo, n. 58, mar. 2000, p. 112-116.

CINTRA, Antonio Carlos de Araújo; DINAMARCO, Cândido Rangel; GRINOVER, Ada Pellegrini. Teoria geral do processo. 16. ed. São Paulo: Malheiros, 2000. 
CIPRIANI, Simonetta. La protezione penale della riservatezza in diritto comparato italiano e francese. Rivista Italiana di Diritto e Procedura Penale, Milano, p. 866-934, 1997.

CLIMENT DURÁN, Carlos. La prueba penal, Valencia: Tirant lo Blanch, 1999.

COLTRO, Antônio Carlos Mathias. O silêncio, a presunção de inocência e sua valoração. Justiça Penal, São Paulo, v. 6, p. 291-305, 1999.

COMPARATO, Fábio Konder. A afirmação histórica dos direitos humanos. São Paulo: Saraiva, 1999.

CONSO, Giovanni. Colloqui com l'imputato detenuto e diritto di difesa. Archivio Penale, Roma, p. 242-243, 1970.

. Considerazioni in tema di contraddittorio nel processo penale italiano. Rivista Italiana di Diritto e Procedura Penale, Milano, p. 405-418, 1966.

. Inizio delle indagini e diritto di difesa. Archivio Penale, Roma, v. 26, p. 139-141, jan./fev. 1970.

Riformare la difesa d'ufficio. Archivio Penale, Roma, p. 256-257, 1969.

CONSOLO, Giovanni Cesaro. Trattato della prova per testemoni e del relativo procedimento d'esame. Torino: UTET, 1904.

CORDERO, Franco. Procedura penale. 4. ed. Milano: Giuffrè, 1998.

. Prove illecite nel processo penale. Rivista Italiana di Diritto e Procedura Penale, Milano, p. 32-55, 1961.

Riflessioni in tema di nullità assolute. Rivista Italiana di Diritto e Procedura Penale, Milano, p. 238-256, 1958.

CÓRDOBA, Gabriela E. Nemo tenetur se ipsum accusare, ¿principio de pasividad? Estudios sobre justicia penal: homenaje al Profesor Julio B. Maier. Buenos Aires: Editores del Puerto, 2005.

CORSO, Piermaria. Diritto al silenzio: garanzia da difendere o ingombro processuale da rimuovere? L'Indice Penale, Padova, p. 1077-1094, set./dez. 1999.

COSTA, JEAN-PAUL. The european court of human rights and its recent case-law. Texas International Law Journal, Volume 38, Issue 3, 2003. 
COTTERRELL, Roger. Comparative law and legal culture. In: REIMANN, Mathias; ZIMMERMANN, Reinhard. The Oxford handbook of comparative law. Oxford: Oxford University Press, 2006, p. 710-737.

DALIA, Andrea Antonio; FERRAIOLI, Marzia. Manuale di diritto processuale penale. 4. ed. Padova: CEDAM, 2001.

DAMAŠKA, Mirjan R. The faces of justice and state authority - a comparative approach of the legal process. United States of America: Yale University Press, 1986.

DANNEMANN, Gerhard. Comparative law: study of similarities or differences. In: REIMANN, Mathias; ZIMMERMANN, Reinhard. The Oxford handbook of comparative law. Oxford: Oxford University Press, 2006, p. 384-419.

DEGANELLO, Mario. Il diritto di difesa: garanzia da rimeditare nell'ordinamento federale nordamericano. Rivista Italiana di Diritto e Procedura Penale, Milano, p. 908-960, 1994.

DELMAS-MARTY, Mireille. Dal codice penale ai diritti dell'uomo. Milano: Giuffrè, 1992.

. La prova penale. L'Indice Penale, Padova, p. 609-628, 1996.

. Procédures pénales d’Europe. Paris: Universidade da França, 1995.

DE MARSICO, Alfredo. Diritto processuale penale. 4. ed. integrata e aggiornata dal Prof. Gian Domenico Pisapia. Napoli: Jovene, 1966.

DERSHOWITZ, Alan M. Why terrorism works: understanding the threat, responding to the challenge. Yale University Press, 2002.

DIAS, Jorge de Figueiredo. Direito processual penal. Coimbra: Coimbra $1^{\text {a }}$ ed., reimpressão, 2004.

DIAS NETO, Theodomiro. O direito ao silêncio: tratamento nos direitos alemão e norteamericano. Revista Brasileira de Ciências Criminais, São Paulo, v. 19, p. 179-204, jul./set. 1997.

DINAMARCO, Cândido Rangel. Instituições de direito processual civil. $6^{\mathrm{a}}$ ed., São Paulo: Malheiros Editores, 2009, vol. I e II.

DOMINIONI, Oreste. In tema di nuova prova scientifica. In: Diritto penale e processo: mensile di giurisprudenza, legislazione e dottrina, n. 9, set. 2001, p. 1061-1065.

. La prova penale scientifica. Milano: Giuffrè, 2006. 
DOTTI, René Ariel. A liberdade e o direito à intimidade. Revista de Informação Legislativa, Brasília, n. 66, p. 125-151, abr.jun. 1980.

DWYER Amy S. The Inter-American Court of Human Rights: towards establishing an effective regional contentious jurisdiction. 13 B.C. Int'l \& Comp. L. Rev. 127 (1990), disponível em http://lawdigitalcommons.bc.edu/iclr/vol13/iss1/6, acesso em 23 de dezembro de 2015.

ELLIS, Jaye. General principles and comparative law. European Journal of International Law (Eur J Int Law) 22: 949-971, 2011.

ENCINAS, Emilio Eiranova. Código penal alemán stgb, código procesal penal alemán, stpo. Madrid: Marcial Pons, 2000.

ESPÍNDOLA, Ruy Samuel. Conceito de princípios constitucionais. São Paulo: Revista dos Tribunais, 1999.

FELICIONI, Paola. Brevi note sul rapporto fra diritto al silenzio e accompagnamento coattivo dell'imputato per il confronto. Cassazione Penale, n. 1989/1990, p. 3467-3478, 1995.

. Considerazioni sugli accertamenti coattivi nel processo penale: lineamenti costituzionali e prospettive di riforma. L'Indice Penale, Padova, p. 495-526, maio/ago. 1999.

FENECH, Miguel. Derecho procesal penal. Barcelona: Labor, 1952. v. 1. . El proceso penal. Barcelona: Bosch, 1956.

FERNANDES, Antonio Scarance. Processo penal constitucional. 2. ed. São Paulo: Revista dos Tribunais, 2000.

FERRAJOLI, Luigi. Diritto e ragione: teoria del garantismo penale. 4. ed. Roma: Laterza, 1997.

FERREIRA, Ivette Senise. A intimidade e o direito penal. Revista Brasileira de Ciências Criminais, São Paulo, v. 5, p. 96-106, jan./mar. 1994.

FERREIRA, Manuel Cavaleiro de. Curso de processo penal. Lisboa: Danúbio, 1986. v. 1. FERREIRA FILHO, Manoel Gonçalves. Comentários à Constituição Brasileira de 1988. São Paulo: Saraiva, 1990. v. 1.

. Direitos humanos fundamentais. 4. ed. São Paulo: Saraiva, 2000. 
FLORES, Marcelo Marcante. Apontamentos sobre os sistemas processuais e a incompatibilidade (lógica) da nova redação do artigo 156 do código de processo penal com o sistema acusatório. Revista IOB de Direito Penal e Processual Penal, n. 53, p. 4256, dez-jan. 2009.

FLORIAN, Eugenio. Delle prove penali. Milano: Francesco Vallardi, 1924. v. 1 e 2.

FORZA, Antonio. L'approccio convenzionlista del sapere giuridico e gli apporti delle neuroscienze nel proceso. In: CATALDO NEUBURGER, Luisella de. (Org.) La prova scientifica nel processo penale. Padova: Cedam, 2007, p. 359-380.

FRANCO, Alberto Silva et al. Código penal e sua interpretação jurisprudencial. 6. ed. São Paulo: Revista dos Tribunais, 1997.

FRANCO, Ary de Azevedo. Código de processo penal. 7. ed. Rio de Janeiro: Forense, 1960. v. 1.

GAROFOLI, Vincenzo. Presunzione d'innocenza e considerazioni di non colpevolezza. La fungibilità delle due formulazioni. Rivista Italiana di Diritto e Procedura Penale, Milano, p. 1168-1200, out./dez. 1998.

GENTILE, Dominic P. Il diritto delle prove penali. In: Il processo penale negli stati uniti d'america. Coord. AMODIO, Enio. BASSIOUNI, M. Cherif. Milano: Giufrè Editore, 1988.

GERARDS, Janneke. Advisory opinions, preliminary rulings, and the new protocol no. 16 to the european convention of human rights, a comparative and critical appraisal. Maastricht Journal of European and Comparative Law, vol. 21, issue 4 (2014), p. 633.

GIACCA, Mariuccia. L'esame dell'imputato nell'esperienza comparatistica: spunti problematici. Rivista Italiana di Diritto e Procedura Penale, Milano, p. 165-182, 1996.

GIACOMOLLI, Nereu José. O devido processo penal: abordagem conforme a Constituição Federal e o Pacto de São José da Costa Rica. São Paulo: Atlas, 2014.

GLESS, Sabine; MARTIN, Jeannine. The comparative method in european courts: a comparison between the cjeu and ecthr. Bergen Journal of Criminal Law \& Criminal Justice, Vol. 1. S. 36-52, 2013.

GOMES, José Carlos. Estrutura das organizações criminosas. Revista Brasileira de Ciências Criminais, São Paulo, v. 22, p. 125-129, abr./jun. 1998. 
GOMES, Luiz Flávio; CERVINI, Raúl. Crime organizado. 2. ed. São Paulo: Revista dos Tribunais, 1997.

GOMES FILHO, Antonio Magalhães. Presunção de inocência e prisão cautelar, São Paulo: Saraiva, 1991.

. Direito à prova no processo penal, São Paulo: RT, 1997.

. A motivação das decisões penais, 2 ed. São Paulo: RT, 2013.

. Méthodes interdites et preuves de façon illicite, "in" Procedural Justice - XIV.

IAPL World Congress, Gieseking-Verlag, Bielefeld, 2014, p. 700-716.

Proibição das provas ilícitas na Constituição de 1988. In: MORAES, Alexandre de. (Coord.). Os 10 anos da Constituição Federal. São Paulo: Atlas, 1999.

Provas - Lei 11.690, de 09.06.2008. In MOURA, Maria Thereza Rocha de Assis

(Coord.). As Reformas no Processo Penal. As novas Leis de 2008 e os Projetos de Reforma. São Paulo: RT, 2008.

. Notas sobre a terminologia da prova (reflexos no processo penal brasileiro). In Estudos em homenagem à Professora Ada Pellegrini Grinover, São Paulo, DPJ, 2005, p. 303-318.

. O princípio da presunção de inocência na Constituição de 1988 e na Convenção Americana de Direitos Humanos (Pacto de São José da Costa Rica). Revista do Advogado, São Paulo, n. 142, p. 30-34, abr. 1994.

GOMES FILHO, Antonio Magalhães; BADARÓ, Gustavo Henrique Righi Ivahy. "Prova e sucedâneos de prova no processo penal brasileiro" (em co-autoria com Antonio Magalhães Gomes Filho. Revista Brasileira de Ciências Criminais. São Paulo, Revista dos Tribunais, n. 65 , p. 175-208, mar./abr. 2007.

; PRADO, Geraldo; BADARÓ, Gustavo Henrique Righi Ivahy; MOURA, Maria Thereza Rocha de Assis; FERNANDES, Og. In: Og Fernandes. (Org.). Medidas Cautelares no Processo Penal: comentários à Lei 12.403, de 04.05.2011. São Paulo: RT, 2011.

GONÇALVEZ, Manuel Lopes Maia. Código de processo penal. 6. ed. Coimbra: Almedina, 1994.

GRECO FILHO, Vicente. Manual de processo penal. São Paulo: Saraiva, 1991. 
GREEN, Michael Steven. The privilege's last stand: the privilege against selfincrimination and the right to rebel against the state. (1999). Faculty Publications. Paper 176. Disponível em http://scholarship.law.wm.edu/facpubs/176, acesso em 18 de fevereiro de 2015.

GREENAWALT, R. Kent. Silence as a Moral and Constitutional Right. 23 Wm. \& Mary L. Rev. 15 (1981). Disponível em http://scholarship.law.wm.edu/wmlr/vol23/iss1/3, acesso em 12 de outubro de 2016.

GREVI, Vittorio. Dichiarazioni dell'imputato sul fatto altrui, diritto al silenzio e garanzia del contraddittorio. Rivista Italiana di Diritto e Procedura Penale, Milano, p. 821-856, jul./set. 1999.

Facoltà di non rispondere delle persone esaminate ex art. $210 \mathrm{cpp}$ e lettura dei verbali di precedenti dichiarazioni. Rivista Italiana di Diritto e Procedura Penale, Milano, p. 1123-1131, 1992.

. Il diritto al silenzio dell'imputato sul fatto proprio e sul fatto altrui. Rivista Italiana di Diritto e Procedura Penale, Milano, p. 1129-1150, 1998.

. Le "dichiarazioni rese dal coimputato" nel nuovo Codice di Procedura Penale. Rivista Italiana di Diritto e Procedura Penale, Milano, p. 1150-1186, 1991.

. “Nemo tenetur se detegere”. Milano: Giuffrè, 1972.

GRIFFIN, Lissa, Is silence sacred? The vulnerability of Griffin v. California in a terrorist world, 15 Wm. \& Mary Bill Rts. J. 927 (2007). Disponível em http://digitalcommons.pace.edu/lawfaculty/469/, acesso em 18 de fevereiro de 2015.

GRINOVER, Ada Pellegrini. A iniciativa instrutória do juiz no processo penal acusatório. Doutrina, Instituto de Direito, v. 7, p. 188-199, 1999.

- A legislação brasileira em face do crime organizado. Revista Brasileira de Ciências Criminais, São Paulo, v. 20, p. 59-69, out./dez. 1997.

. A marcha do processo. Rio de Janeiro: Forense Universitária, 2000.

- As garantias constitucionais do direito de ação. São Paulo: Revista dos Tribunais, 1973.

. Aspectos processuais da responsabilidade penal da pessoa jurídica. In: Temas atuais de direito criminal. São Paulo: Revista dos Tribunais, 1999. v. 2. 
Aspectos processuais da responsabilidade penal da pessoa jurídica. In: $O$ processo: estudos e pareceres. 2. ed. São Paulo: DPJ Editora, 2009.

. As provas ilícitas na Constituição. In: O processo em evolução. 2. ed. Rio de Janeiro: Forense, 1998.

- Defesa, contraditório, igualdade e "par condicio" na ótica do processo de estrutura cooperatória. In: Novas tendências do direito processual. Rio de Janeiro: Forense Universitária, 1990.

Interceptações telefônicas e gravações clandestinas no processo penal. In: Novas tendências do direito processual. São Paulo: Forense, 1990.

. Liberdades públicas e processo penal. 2. ed. São Paulo: Revista dos Tribunais, 1982.

- O conteúdo da garantia do contraditório. In: Novas tendências do direito processual penal. Rio de Janeiro: Forense Universitária, 1990.

. O interrogatório do réu e direito ao silêncio. Ciência Penal, São Paulo, v. 1, p. $15-31,1976$.

GRINOVER, Ada Pellegrini; FERNANDES, Antonio Scarance; GOMES FILHO, Antonio Magalhães. As nulidades no processo penal. 4. ed. São Paulo: Malheiros, 1995; 12. ed. São Paulo: Revista dos Tribunais, 2011.

HAGE, Jaap. Comparative law and legal science. Maastricht European Private Law Institute Working Paper No. 2011/11. Disponível em: http://ssrn.com/abstract=1600108, acesso em 7 de março de 2016.

HASSEMER, Winfried. Límites del estado de derecho para el combate contra la criminalidad organizada. Revista Brasileira de Ciências Criminais, São Paulo, v. 23, p. 2530, jul./set. 1998.

HELMHOLZ, R. H. et al. The privilege against self-incrimination: its origins and development. Chicago: Universidade de Chicago, 1997.

HELMHOLZ, R. H. Origins of the privilege against self-incrimination: the role of the European Ius Commune. 65 New York University Law Review 962 (1990).

HENDLER, Edmundo S.; TEDESCO, Ignacio F. La declaración del imputado y una perspectiva histórica comparada: la justicia criminal en francia e Inglaterra. In: 
HENDLER, Edmundo S. (Coord.). Sistemas procesales penales comparados. Buenos Aires: Ad-Hoc, 1999, p. 385 e ss.

HERENCIA CARRASCO, Salvador. El derecho de defensa en la jurisprudencia de la corte interamericana de derechos humanos. In: Sistema Interamericano de Protección de los Derechos Humanos y Derecho Penal Internacional - Volumen 1. Montevideo: Fundación Konrad Adenauer \& Georg-August-Universität-Göttingen, 2010.

HERNÁNDES, Ángel Gil. Intervenciones corporales y derechos fundamentales. Madrid: Colex, 1995.

HOBSON, Charles. The minimalist privilege. NYU Journal of Law \& Liberty, vol. 1 n. 2. Disponível em http://www.law.nyu.edu/sites/default/files/ECM_PRO_060914.pdf, acesso em 10.06.2015.

IBBETSON, David John. Common law and ius commune. Selden Society, 2001.

HUSA, Jaakko. About the methodology of comparative law - some comments concerning the wonderland... Maastricht Working Papers - Faculty of Law Iss. 2007/5 (2007).

JACKSON, John. Re-conceptualizing the right of silence as an effective fair trial standard. The International and Comparative Law Quarterly 58 (4). 2009. Cambridge University Press: 835-61. http://www.jstor.org/stable/25622247, acesso em 24.11.2015.

JANSEN, Nils. Comparative law and comparative knowledge. In: REIMANN, Mathias; ZIMMERMANN, Reinhard. The Oxford handbook of comparative law. Oxford: Oxford University Press, 2006, p. 305-338.

JUNG, Heike. EL proceso penal, conceptos, modelos y supuestos básicos. In: AMBOS, Kai; LYNETT, Eduardo Montealegre (Coord.). Constitución y sistema acusatorio. Un estudio de derecho comparado. Bogotá: Universidad Externado de Colombia, ano de publicação omisso, p. 95-107.

LANGBEIN, John H. The historical origins of the privilege against self-incrimination at common law. Faculty Scholarship Series. Paper 550, disponível em http://digitalcommons.law.yale.edu/fss_papers/550, acesso em 18 de fevereiro de 2015.

LEONE, Giovanni. Manuale di diritto processuale penale. 13. ed. Napoli: Jovene, 1988.

LOCKHART, William B. et al. The American Constitution. 8. ed. St. Paul: West Publishing Co., 1996. 
MAIER, Julio B. J. Derecho procesal penal: Tomo I - fundamentos. $2^{\mathrm{a}}$ ed., $3^{\mathrm{a}}$ reimp., Buenos Aires: Editores del Puerto, 2004.

. Derecho procesal penal: Tomo II - parte general. $1^{\text {a }}$ ed., Buenos Aires: Editores del Puerto, 2003.

_. Antologia - el proceso penal contemporâneo. $1^{\mathrm{a}}$ ed., Peru: Palestra Editores, 2008.

MALIK, Preksha. Adverse inference from silence: an urgent need in rape cases (September 18, 2012). Disponível em SSRN: http://ssrn.com/abstract=2148240, acesso em 27.01.2015.

MANZILLO, Fabio Foglia. "Nemo tenetur se detegere": um limite all'applicazione del reato di falso in bilancio? Rivista Trimestrale di Diritto Penale dell'Economia, Milano, p. 237-262, jan./jun. 1999.

MANZINI, Vincenzo. Istituzioni di diritto processuale penale. Padova: CEDAM, 1950.

. Trattato di diritto processuale penale italiano secondo il nuovo Codice. Torino: UTET, 1931-1932. v. 1, 2 e 3.

MARQUES, José Frederico. Elementos de direito processual penal. 2. ed. Rio de Janeiro: Forense, 1961. v. 2.

MARTÍN, M. Isabel Huertas. El sujeto pasivo del proceso penal como objeto de la prueba. Barcelona: Jose Maria Bosch Editor: 1999.

MAZZUOLI, Valério de Oliveira. O sistema regional europeu de proteção dos direitos humanos. Cadernos da Escola de Direito e Relações Internacionais. Curitiba, n. 13. V. 1., p. 32-58.

MCKASKLE, Paul L. The european court of human rights: what it is, how it works, and its future. 40 University of San Francisco Law Review 1 (2005).

MELLADO, Jose María Asencio. Prueba prohibida y prueba preconstituída. Madrid: Trivium, 1989.

MELLO, Celso Antônio Bandeira de. Curso de direito administrativo. 12. ed. São Paulo: Malheiros, 2000.

MELlO FILHO, José Celso de. A tutela judicial da liberdade. RT, São Paulo, v. 526, p. 291-302, ago. 1979. 
MENDES, Gilmar Ferreira. Controle de constitucionalidade: aspectos jurídicos e políticos. São Paulo: Saraiva, 1990.

. Direitos fundamentais e controle da constitucionalidade. São Paulo, Instituto Brasileiro de Direito Constitucional, 1998.

. Proporcionalidade na jurisprudência do Supremo Tribunal Federal. Repertório IOB de Jurisprudência, n. 23, p. 469-475, dez. 1994.

; BRANCO, Paulo Gustavo Gonet. Curso de direito constitucional. 10 a ed., São Paulo: Saraiva, 2015.

MENDONÇA, Rachel Pinheiro de Andrade. Provas ilícitas: limites à licitude probatória. Rio de Janeiro: Lumen Juris, 2001.

MICHAELS, Ralf. The functional method. In: REIMANN, Mathias; ZIMMERMANN, Reinhard. The Oxford handbook of comparative law. Oxford: Oxford University Press, 2006, p. 340-382.

MINVIELLE, Bernadette. La Convención Americana sobre Derechos Humanos (Pacto de San José de Costa Rica) y el enjuiciamiento penal, In: Doctrina Penal - teoría y práctica en las ciencias penales, $n^{\circ} 41$ a 44. Buenos Aires: Ediciones Depalma, 1988.

MIRFIELD, Peter. Silence, confessions and improperly obtained evidence, Oxford: Clarendon, 2003.

MOISIDIS, Cosmas. Criminal discovery: from truth to proof and back again. Sydney Institute of Criminology, Australia, 2008.

MÖLLER, Kai. From constitutional to human rights: on the moral structure of international human rights. Global Constitutionalism, 3 (3), pp. 373-403, Cambridge University Press, 2014, disponível em http://eprints.lse.ac.uk/59305/, acesso em 25.05.2015.

MONATERI, Pier Giuseppe. Methods in comparative law: an intellectual overview, 25 de setembro de 2012. Disponível em: http://ssrn.com/abstract=2151819, acesso em 7 de março de 2016.

MORAES, Alexandre de. Direitos humanos fundamentais e a Constituição de 1988. In: Os 10 anos da Constituição Federal. São Paulo: Atlas, 1999. 
MORAES, Maurício Zanoide de. Presunção de inocência no processo penal brasileiro: análise de sua estrutura normativa para a elaboração legislativa e para a decisão judicial. Rio de Janeiro: Lumen Juris, 2010.

MOREIRA, José Carlos Barbosa. A Constituição e as provas ilicitamente obtidas. RF, Rio de Janeiro, v. 337, p. 125-134, jan./mar. 1997.

- Processo civil e direito à preservação da intimidade. In: Temas de direito processual. São Paulo: Saraiva, 1980.

MOURA, Maria Thereza Rocha de Assis; BASTOS, Cleunice A. Valentim. Defesa penal: direito ou garantia. Revista Brasileira de Ciências Criminais, São Paulo, v. 4, p. 110-125, out./dez. 1993.

MOURA, Maria Thereza Rocha de Assis; MORAES, Maurício Zanoide de. Direito ao silêncio no interrogatório. Revista Brasileira de Ciências Criminais, São Paulo, v. 6, p. $135-141$.

NERY JR., Nelson. Proibição da prova ilícita - Novas tendências do direito $\left(\mathrm{CF}\right.$, art. $5^{\circ}$, LVI). In: Os 10 anos da Constituição Federal. São Paulo: Atlas, 1999.

- Princípios do processo na constituição federal: processo civil, penal e administrativo. 9. ed. São Paulo: RT, 2009.

. Princípios fundamentais - Teoria geral dos recursos. 4. ed. São Paulo: RT, 1997.

NEVES, Serrano. O direito de calar. Rio de Janeiro: Freitas Bastos, 1960.

NORONHA, Edgard Magalhães. Curso de direito processual penal. 25. ed. São Paulo: Saraiva, 1997.

NUCCI, Guilherme de Souza. Manual de processo penal e execução penal. 13. ed. Rio de Janeiro: Forense, 2016.

NUVOLONE, Pietro. La riforma del paragrafo $2^{\circ}$ del Codice Penale germanico. Rivista Italiana di Diritto Penale, Padova, p. 530-561, 1938.

La riforma del processo penale in Italia e in Germania. Rivista Italiana di Diritto e Procedura Penale, Milano, p. 345-359, 1962.

OLIVEIRA, Eugênio Pacelli de. Curso de processo penal. 18ª ed. São Paulo: Atlas, 2014. 
O'REILLY, Gregory W. England limits the right to silence and moves towards an inquisitorial system of justice. In The Journal of Criminal Law \& Criminology, vol. 85, 1994.

ORGANIZATION OF AMERICAN STATES INTER-AMERICAN COURT OF HUMAN RIGHTS. Basic documents pertaining to human rights in the Inter-American system: (updated to Febuary 2012). Corte Interamericana de Derechos Humanos, - San José: Costa Rica, 2012.

ORLANDI, Renzo. Coimputato e imputato di reato connesso nel processo germanico. In: Le nuove leggi penali. Milano: CEDAM, 1998.

OSBORN, Albert S. The problem of proof. Albany: Boyd Print Company, 1947.

PADILLA, David J. The Inter-American Commission on Human Rights of the Organization of American States: A Case Study. American University International Law Review 9, no. 1 (1993): 95-115.

PALMER, Vernon Valentine. From lerotholi to lando: some examples of comparative law methodology. Global Jurist Frontiers, volume 4(2), 2004.

PARKER, Mary C. "Other treaties": the inter-american court of human rights defines its advisory jurisdiction. 33 AM. U. L. REV. 211, 211-13 (1983).

PEREZ, Jesus Gonzalez. La dignidad de la persona. Madrid: Editorial Civitas S.A., 1986.

PERINI, Andrea. Ai margini dell'esigibilità: "nemo tenetur se detegere" e false comunicazioni sociali. Rivista Italiana di Diritto e Procedura Penale, Milano, p. 538-586, abr./jun. 1999.

PHIPSON, Sidney L. 'Real' evidence. The Yale Law Journal 29, no. 7 (1920): 705-17.

PIERANGELI, José Henrique. Processo penal: evolução histórica e fontes legislativas. Bauru: Jalovi, 1983.

PIOVESAN, Flávia. Direitos humanos e o direito constitucional internacional. 10. ed. São Paulo: Saraiva, 2009.

. Temas de direitos humanos. 7. ed. São Paulo: Saraiva, 2014.

- Direitos humanos e o princípio da dignidade humana. In: LEITE, George Salomão (Coord.). Dos princípios constitucionais - considerações em torno das normas principiológicas da constituição. São Paulo: Malheiros, 2003. 
PITOMBO, Cleunice A. Valentim Bastos. Considerações sobre a tutela da intimidade e a vida privada no processo penal. Revista Brasileira de Ciências Criminais, São Paulo, v. 26, p. 59-79, abr./jun. 1999.

. Da busca e apreensão no processo penal. São Paulo: Revista dos Tribunais, 1999.

PITOMBO, Sérgio Marcos de Moraes. O juiz penal e a pesquisa da verdade material. In: Processo penal e Constituição Federal. São Paulo: Apamagis, 1993.

PUCCIARELLO, Mariana. Derecho a no autoincriminarse y deber de colaborar en el ámbito tributario. Buenos Aires: Ad Hoc, 2011.

PULITANO, Domenico. "Nemo tenetur se detegere": quali profili di diritto sostanziale? Rivista Italiana di Diritto e Procedura Penale, Milano, p. 1271-1301, out./dez. 1999.

QUEIJO, Maria Elizabeth. Hermenêutica e interpretação constitucional e o direito processual penal. Hermenêutica constitucional - homenagem aos 22 anos do Grupo de Estudo Maria Garcia. Florianópolis: Conceito Editorial, 2010.

. Nova tentativa de supressão de direito fundamental: a pretendida imposição do dever de dizer a verdade ao acusado sob pena de cometer perjúrio. Boletim IBCCrim, São Paulo, n. 202, p. 9-10, set. 2009.

. O direito de não produzir prova contra si mesmo: o princípio nemo tenetur se detegere e suas decorrências no processo penal. 2a ed., São Paulo: Saraiva, 2012.

QUIROGA, Jacobo López Barja de. Tratado de derecho procesal penal. Navarra: Editorial Aranzadi AS, 2004.

RAMOS, André de Carvalho. Limites ao poder de investigar e o privilégio contra a autoincriminação à luz do direito constitucional e do direito internacional dos direitos humanos. In: Limites constitucionais da investigação. Coord. CUNHA, Rogério Sanches. TAQUES, Pedro. GOMES, Luiz Flávio. São Paulo: Revista dos Tribunais, 2009.

RANGEL, Paulo. Direito processual penal. 20a ed., São Paulo: Atlas, 2012.

REALE JÚNIOR, Miguel. Crime organizado e crime econômico. Revista Brasileira de Ciências Criminais, São Paulo, v. 13, p. 182-190, jan./mar. 1996.

ROXIN, Claus. La prohibición de autoincriminación y de las escuchas domiciliarias. Buenos Aires: Hammurabi, 2008. 
La evolución de la política criminal, el derecho penal y el proceso penal. Valencia: Tirant Lo Blanch, 2000.

SAAD, Marta. O direito de defesa no inquérito policial. São Paulo, RT, 2004.

SANTOS, Moacyr Amaral. Prova judiciária no cível e comercial. 2. ed. São Paulo. Max Limonad, s.d., v. 5.

. Primeiras linhas de direito processual civil. 21ª ed. São Paulo: Saraiva, 1999, vol. 1.

SARAIVA, Railda. A Constituição de 1988 e o ordenamento jurídico-penal brasileiro. Rio de Janeiro: Forense, 1992.

SARLET, Ingo Wolfgang. Dignidade da pessoa humana e direitos fundamentais na Constituição Federal de 1988. $9^{a}$ ed., Porto Alegre: Livraria do Advogado Editora, 2011.

. Algumas notas em torno da relação entre o princípio da dignidade da pessoa humana e os direitos fundamentais na ordem constitucional brasileira. In: LEITE, George Salomão (Coord.). Dos princípios constitucionais - considerações em torno das normas principiológicas da constituição. São Paulo: Malheiros, 2003.

SCELLA, Andrea. L'inutilizzabilità della prova nel sistema del processo penale. Rivista Italiana di Diritto e Procedura Penale, Milano, p. 203-219, 1992.

SEGADO, Francisco Fernandez. La dogmatica de los derechos humanos. Lima: Ediciones Juridicas, 1994.

SILVA, José Afonso da. A dignidade da pessoa humana como valor supremo da democracia. Revista de Direito Administrativo, Rio de Janeiro, v. 212, p. 89-94, abr./jun. 1998.

. Curso de direito constitucional positivo. 25. ed. São Paulo: Malheiros, 2005.

SIRACUSANO, Delfino. Prova. In: Enciclopedia giuridica. Roma: Treccani, 1989. v. 25.

SIRACUSANO, D.; GALATI, A.; TRANCHINA, G.; ZAPPALÀ, E. Diritto processuale penale. 3. ed. Milano: Giuffrè, 1996. v.1 e 2.

SOARES, Guido Fernando Silva. Common law. São Paulo: Revista dos Tribunais, 1999.

SPIRITO, Pedro. Giuramento (diritto canonico e diritto ecclesiastico). In: Enciclopedia giuridica. Roma, Treccani, 1989. v. 15. 
STEINER, Sylvia Helena de Figueiredo. A Convenção Americana sobre Direitos Humanos e sua integração ao processo penal brasileiro. São Paulo: Revista dos Tribunais, 2000.

TARUFFO, Michele. La prueba de los hechos. $4^{\mathrm{a}}$ ed. Madrid: Editorial Trotta, 2011.

. Uma simples verdade - o juiz e a construção dos fatos. Madrid: Marcail Pons, 2012.

. Conoscenza scientifica e decisione giudiziaria: profili generali. In: Decisione giudiziaria e verità scientifica, Milano, Giuffrè, 2005, p. 3-23.

TEDESCO, Ignacio F. La libertad de declaración del imputado. Un análisis histórico comparativo. in HENDLER, Edmundo S. (comp.), Garantías penales y procesales penales. Una perspectiva histórico-comparada. Buenos Aires, Editores del Puerto 2001.

THAMAN, Stephen C. La dicotomía acusatorio-inquisitivo en la jurisprudencia constitucional de Estados Unidos. In: AMBOS, Kai; LYNETT, Eduardo Montealegre (Coord.). Constitución y sistema acusatorio. Un estudio de derecho comparado. Bogotá: Universidad Externado de Colombia, ano de publicação omisso, p. 159-175.

THUNS, Gilberto. O mito da verdade e os sistemas processuais, In: CARVALHO, Salo de (Org.). Leituras Constitucionais do Sistema Penal Contemporâneo. Lumen Juris: Rio de Janeiro, 2004. p. 153 e ss.

TORNAGHI, Hélio. Curso de processo penal. 7. ed. São Paulo: Saraiva, 1990. v. 1. Instituições de processo penal. 2. ed. São Paulo: Saraiva, 1977. V. 2.

TOURINHO FILHO, Fernando da Costa. Processo penal. 20. ed. São Paulo: Saraiva, 1998. v. 3.

. Código de processo penal comentado. 13a ed., São Paulo: Saraiva, 2010. v. 1 e 2.

TRECHSEL, Stefan. Human rights in criminal proceedings. Oxford University Press, 2005 .

TRINDADE, Antônio Augusto Cançado. A proteção internacional dos direitos humanos. São Paulo: Saraiva, 1991.

TUCCI, Rogério Lauria. Direitos e garantias individuais no processo penal brasileiro. $4^{\mathrm{a}}$ ed., São Paulo: Revista dos Tribunais, 2011.

. Lineamentos do processo penal romano. São Paulo: Ed. USP, 1976. 
Princípio e regras orientadoras do novo processo penal brasileiro. Rio de Janeiro: Forense, 1986.

UBERTIS, Giulio. La ricerca della verità giudiziale. In: La conoscenza del fatto nel processo penale. Milano: Giuffrè, 1992.

VAGNOLI, Elena Terrosi. L'identificazione genetica (DNA profiling) nella recente giurisprudenza statunitense. La Giustizia Penale, p. 85-96, 1995.

VELOSO, Zeno. Controle jurisdicional de constitucionalidade. Belém: CEJUP, 1999.

VERRI, Pietro. Osservazioni sulla tortura. Milano: RCS Libri, 1998.

VETTORI, Cecilia. Diritto dell'imputato a confrontarsi con colui che lo accusa e diritto al silenzio: l'ordinamento inglese. In: Le nuove leggi penali. Milano: CEDAM, 1998.

VÍQUEZ, Fernando Castillo; LOAIZA, Olman Rodríguez; RODRÍGUEZ, Graciela Arguedas. Convención americana sobre derechos humanos anotada y concordada con la jurisprudencia de la corte interamericana de derechos humanos. Costa Rica: Corte Suprema de Justicia. Escuela Judicial, 2013.

WOLTER, Jürgen. Dignidad humana y liberdad en el proceso penal. In: AMBOS, Kai; LYNETT, Eduardo Montealegre (Coord.). Constitución y sistema acusatorio. Un estudio de derecho comparado. Bogotá: Universidad Externado de Colombia, ano de publicação omisso, p. 227-262.

ZILLI, Marcos Alexandre Coelho. A iniciativa instrutória do juiz no processo penal. São Paulo: Revista dos Tribunais, 2003.

\section{CASOS UTILIZADOS - CORTE INTERAMERICANA DE DIREITOS HUMANOS}

\#

19 Comerciantes v. Colombia, de 5 de julho de 2004

A

Acosta Calderón v. Equador, de 24 de junho de 2005 
B

Baena Ricardo y otros v. Panamá, de 2 de fevereiro de 2001

Bámaca Velásquez v. Guatemala, de 25 de novembro de 2000

Bayarri vs. Argentina, de 30 de outubro de 2008

Blake v. Guatemala, de 24 de janeiro de 1998

Blanco Romero y otros v. Venezuela, de 28 de novembro de 2005

Barrios Altos v. Peru, de 14 de março de 2001

C

Cantoral Benavides v. Perú, de 18 agosto de 2000

Cantos v. Argentina, de 28 de novembro de 2002

Carpio Nicolle y otros v. Guatemala, de 22 de novembro de 2004

Castillo Petruzzi y otros v. Perú, de 30 de maio de 1999

Cesti Hurtado v. Perú, de 29 de setembro de 1999

Chaparro Álvarez y Lapo Íñiguez v. Ecuador, de 21 de novembro de 2007

Comunidad Mayagna (Sumo) Awas Tingni v Nicaragua, de 31 de agosto de 2001

Comunidad Moiwana v. Surinam, de 15 de junho de 2015

D

Durand y Ugarte v. Perú, de 28 de maio de 1999

$\mathbf{E}$

Escher e outros v. Brasil, de 6 de julho de 2009

G

García Asto y Ramírez Rojas v. Perú, de 25 de novembro de 2005

Garibaldi v. Brasil, de 23 de setembro de 2009

Gelman v. Uruguai, de 24 de fevereiro de 2011

Godínez Cruz v. Honduras, de 20 de janeiro de 1989

Gomes Lund e Outros (“Guerrilha do Araguaia”) v. Brasil, de 24 de novembro de 2010

González Medina y familiares v. República Dominicana, de 27 de fevereiro de 2012

Gudiel Álvarez y otros (“Diario Militar”) v. Guatemala, de 20 de novembro de 2012

Gutiérrez Soler v. Colombia, de 12 de setembro de 2005 
$\mathbf{H}$

Hermanas Serrano Cruz v. El Salvador, de 01 de março de 2005

Hilaire, Constantine y Benjamin y otros v. Trinidad y Tobago, 21 de junho de 2002

I

Instituto de Reeducación del Menor v. Paraguai, de 2 de setembro de 2004

$\mathbf{J}$

Juan Humberto Sánchez v. Honduras, de 07 de junho de 2003

$\mathbf{L}$

Las Palmeras v. Colombia, de 6 de dezembro de 2001

Loayza Tamayo v. Perú, de 27 de novembro de 1998

López Álvarez v. Honduras, de $1^{\circ}$ de fevereiro de 2006

Lori Berenson Mejía v. Perú, de 25 de novembro de 2004

Los Hermanos Gómez Paquiyauri v. Perú, de 8 de julho de 2004

$\mathbf{M}$

Maritza Urrutia v. Guatemala, de 27 de novembro de 2003

Masacres de El Mozote y lugares aledaños v. El Salvador, de 25 de outubro de 2012

Masacre de Mapiripán v. Colombia, de 15 de setembro de 2005

Masacre de Pueblo Bello v. Colombia, de 31 de janeiro de 2006

Masacres de Río Negro v. Guatemala, de 4 de setembro de 2012

Masacre Plan de Sánchez v. Guatemala, de 19 de novembro de 2004

Myrna Mack Chang v. Guatemala, de 25 de novembro de 2003

$\mathbf{P}$

Palamara Iribarne v. Chile, de 22 de novembro de 2005

Paniagua Morales y otros v. Guatemala, de 08 de março de 1998

$\mathbf{R}$

Raxcacó Reyes v. Guatemala, de 15 de setembro de 2005

Ricardo Canese v. Paraguay, de 31 de agosto de 2004

Rosendo Cantú y otra v. México, de 31 de agosto de 2010 
Suárez Rosero v. Equador, de 12 de novembro 1997

$\mathbf{T}$

Tibi v. Ecuador, de 7 de setembro de 2004

V

Velásquez Rodríguez v. Honduras, de 29 de julho de 1988

Villagrán y otros v. Guatemala, de 19 de novembro de 1999

$\mathbf{X}$

Ximenes Lopes v. Brasil, de 4 de julho de 2006

$\mathbf{Y}$

Yatama v. Paraguai, de 23 de junho de 2005

\section{OPINIÕES CONSULTIVAS - CORTE INTERAMERICANA DE DIREITOS HUMANOS}

a) Opinión Consultiva 3/83 - Restricciones a La Pena de Muerte (arts. 4.2 y 4.4 Convención Americana sobre Derechos Humanos)

b) Opinión Consultiva 9/87 - Garantías Judiciales en Estados de Emergencia (arts. 27.2, 25 y 8 Convención Americana sobre Derechos Humanos)

c) Opinión Consultiva 5/85 - La Colegiación Obligatoria de Periodistas (arts. 13 y 29 Convención Americana sobre Derechos Humanos)

d) Opinión Consultiva 12/91 - Compatibilidad de un Proyecto de Ley con el artículo 8.2.h. de la Convención Americana sobre Derechos Humanos 
e) Opinión Consultiva 16/99 - El derecho a la información sobre la Asistencia Consular en el marco de las garantías del debido proceso legal

f) Opinión Consultiva 17/02 - Condición Jurídica y Derechos Humanos del Niño

g) Opinión Consultiva 18/03 - Condición Jurídica y Derechos de los Migrantes Indocumentados

h) Opinión Consultiva 20/09 - Artículo 55 de la Convención Americana sobre derechos humanos

\section{CASOS UTILIZADOS - CORTE EUROPEIA DE DIREITOS HUMANOS}

A

Abas v. The Netherlands, de 26 de fevereiro de 1997

Aleksandr Zaichenko v. Russia, de 18 de fevereiro de 2010

Allan v. The United Kingdom, de 5 de novembro de 2002

Allen v. The United Kingdom, de 10 de setembro 2002

Ashot Harutyunyan v. Armenia, de 15 de setembro de 2010

Averill v. The United Kingdom, de 6 de junho de 2000

B

Beckles v. The United Kingdom, de 8 de outubro de 2002

Berliński v. Poland, de 20 de setembro de 2002

Bogumil v. Portugal, de 6 de Abril de 2009

Brusco v. France, de 14 de outubro de 2010

Bykov v. Russia, de 19 de março de 2009 
C

Choudhary v. The United Kingdom, de 4 de maio de 1999

Condron v. The United Kingdom, de 2 de agosto de 2000

$\mathbf{F}$

Former King of Greece and others v. Greece, de 23 de novembro de 2000

Former King of Greece and others v. Greece (julgamento just satisfaction), de 28 de novembro de 2002 .

Funke v. France, de 25 de fevereiro de 1993

G

Gäfgen v. Germany, de 1 de junho de 2010

Gladyshev v. Russia, de 30 de outubro de 2009

Gocmen v. Turkey, de 17 de outubro de 2006

Grayson and Barnham v. The United Kingdom, 23 de setembro de 2008

$\mathbf{H}$

Heaney and McGuinness v. Ireland, de 21 de março de 2001

Heglas v. the Czech Republic, de 9 de julho de 2007

\section{I}

I.J.L. and others v. The United Kingdom, de 19 de dezembro de 2000

$\mathbf{J}$

J.B. v. Switzerland, de 3 de maio de 2001

Jalloh v. Germany, de 11 de julho de 2006

John Murray v. The United Kingdom, de 8 de fevereiro de 1996

$\mathbf{K}$

K. v. Austria, de 13 de outubro de 1992

Khan v. The United Kingdom, de 4 de outubro de 2010

King v. The United Kingdom, de 26 de janeiro de 2010 
$\mathbf{L}$

Lee Davies v. Belgium, de 28 de julho de 2009

Levinţa v. Moldova, de 16 de março de 2009

Lingens v. Austria, de 8 de julho de 1986

Lutsenko v. Ukraine, de 3 de julho de 2012

\section{M}

Magee v. The United Kingdom, de 6 junho de 2000

Mamatkulov and Askarov v. Turkey, de 4 de fevereiro de 2005

Marttinen v. Finland, de 21 de abril de 2009

$\mathbf{N}$

Niemietz v. Germany, de 16 de dezembro de 1992

$\mathbf{O}$

O'Halloran and Francis v. The United Kingdom, de 29 de junho de 2007

Osmanağaoğlu v. Turkey, de 21 de julho de 2009

$\mathbf{P}$

Paladi v. Moldova, de 10 de março de 2009

P.G. and J.H. v. The United Kingdom, de 25 de dezembro de 2001

Phillips v. The United Kingdom, de 12 de dezembro de 2001

Pishchalnikov v. Russia, de 24 de setembro de2009

Q

Quinn v. Ireland, de 21 de março de 2001

$\mathbf{R}$

Ramanauskas v. Lithuania, de 5 de fevereiro de 2008

Reyntjens v. Belgium, de 9 de setembro de 1992

S

Salabiaku v. France, de 7 de outubro de 1988

Saunders v. United Kingdom, de 17 de Dezembro de 1996 
Shabelnik v. Ukraine, de 19 de maio de 2009

Shannon v. The United Kingdom, de 4 de janeiro de 2006

Schenk v. Switzerland, 12 de julho de 1988

Serves v. France, de 20 de outubro de 1997

$\mathbf{T}$

Teixeira de Castro v. Portugal, de 9 de junho de 1998

Telfner v. Austria, de 20 de março de 2001

V

Vasileva v. Denmark, de 25 de dezembro de 2003

W

Weh v. Austria, de 8 de julho de 2004

$\mathbf{Y}$

Yusuf Gezer v. Turkey, de 1 de dezembro de 2009

$\mathbf{Z}$

$\mathrm{Z}$ and others v. The United Kingdom, de 10 de maio de 2001

Zhelezov v. Russia, de 23 de abril de 2002 